\title{
Pharmacokinetics and Bioequivalence Comparison of 600 mg Single-Dose Linezolid Oral Suspension and Tablet Formulation in Healthy Chinese Subjects
}

\author{
Jing Zhang ${ }^{1}$, Yingyuan Zhang ${ }^{1}$, Ronnie Wang ${ }^{2}$, Christine Alvey ${ }^{2}$, Qiang Wang ${ }^{2}$, Bharat Damle ${ }^{3}$ and Huifen Faye Wang ${ }^{2 *}$
}

${ }^{1}$ Hua Shan Hospital Affiliated to Fudan University, Shanghai, China

${ }^{2}$ Pfizer Inc., 445 Eastern Point Road, Groton, CT 06340, USA

${ }^{3}$ Pfizer Inc., 235 East 42nd Street, New York, NY 10017, USA

\begin{abstract}
Study background: Linezolid is indicated for the treatment of infections caused by aerobic Gram-positive bacteria. An oral suspension formulation poses an alternative to solid oral formulations in patients with swallowing difficulties, especially pediatric and geriatric patients, or patients with feeding tubes.

Methods: This randomized, open-label, two-way cross-over, clinical pharmacology study in healthy Chinese male subjects evaluated the bioequivalence of single-dose $600 \mathrm{mg}$ linezolid oral suspension to single-dose 600 $\mathrm{mg}$ linezolid film-coated tablet under fasted conditions. Pharmacokinetic blood sampling was carried out at various time points within $48 \mathrm{~h}$ post-dosing and plasma samples were analyzed using a validated high-performance liquid chromatography tandem mass spectrometric method. The primary endpoints were area under plasma concentrationtime curve (AUC) from time zero to the time of the last quantifiable concentration $\left(A \cup C_{\text {last }}\right)$ and maximum plasma concentration $\left(\mathrm{C}_{\max }\right)$ for linezolid.

Results: All 20 enrolled male subjects completed the study (mean age 25 years, mean body mass index $22 \mathrm{~kg} /$ $\mathrm{m}^{2}$ ). The $90 \%$ confidence intervals (Cls) for the ratios of the adjusted geometric means of the primary endpoints, $\mathrm{AUC}_{\text {last }}(97.81 \%[90 \% \mathrm{Cl}, 93.11-102.75 \%])$ and $\mathrm{C}_{\max }(113.67 \%[90 \% \mathrm{Cl}, 105.26-122.75 \%])$, for the oral suspension formulation compared with the oral tablet were fully within the established bioequivalence limits of $80-125 \%$. The two linezolid formulations were well tolerated and no serious adverse event or other significant adverse event was noted.

Conclusions: Based on the results of this study, linezolid $600 \mathrm{mg}$ oral suspension and linezolid $600 \mathrm{mg}$ tablets are anticipated to be therapeutically equivalent and could be switched in subjects without any need for dose modification. Both formulations were safe and well tolerated.
\end{abstract}

Keywords: Linezolid; Pharmacokinetics, Oral suspension; Bioequivalence; Healthy chinese subjects

\begin{abstract}
Abbreviations: AE: Adverse Event; AUC: Area under Plasma Concentration-time Curve; $\mathrm{AUC}_{\text {inf }}$ Area under Plasma Concentration-time Curve from Time Zero Extrapolated to Infinite Time; $\mathrm{AUC}_{\text {last }}$ : Area under Plasma Concentration-time Curve from Time Zero to the Time of the Last Quantifiable Concentration; BMI: Body Mass Index; CI: Confidence Interval; $\mathrm{C}_{\max }$ : Maximum Plasma Concentration; CRU: Clinical Research Unit; CYP: Cytochrome P450; ECG: Electrocardiogram; HPLC-MS/MS: High-performance Liquid Chromatography Tandem Mass Spectrometry; LLOQ: Lower Limit of Quantification; PD: Pharmacodynamics; PK: Pharmacokinetic; SD: Standard Deviation; $\mathrm{t}_{1 / 2}:$ Elimination Half-life; $\mathrm{T}_{\max }:$ Time for Maximum Plasma Concentration
\end{abstract}

\section{Introduction}

Linezolid is a synthetic antibacterial agent from the oxazolidinone class of antibiotics that selectively inhibits bacterial protein synthesis [1-4]. Through a unique mechanism of action, linezolid prevents the formation of an essential component of the bacterial translation process that involves binding to a site on the bacterial $23 \mathrm{~S}$ ribosomal ribonucleic acid of the $50 \mathrm{~S}$ subunit and inhibiting the assembly of a functional 70S initiation complex [1]. Cross-resistance between linezolid and other classes of antibiotics is unlikely $[5,6]$.

Linezolid is approved for the treatment of infections caused by aerobic Gram-positive bacteria, such as nosocomial pneumonia; community-acquired pneumonia; complicated skin and skin structure infections, including diabetic foot infections, without concomitant osteomyelitis; uncomplicated skin and skin structure infections; and vancomycin-resistant Enterococcus faecium infections. Linezolid is available in three formulations: intravenous solution, oral film-coated tablet, and oral suspension [7]. The usual oral doses of linezolid are 10 $\mathrm{mg} / \mathrm{kg}$ every 8 or $12 \mathrm{~h}$ for pediatric patients ( $<12$ years of age) and 400 $\mathrm{mg}$ or $600 \mathrm{mg}$ every $12 \mathrm{~h}$ for adults and adolescents ( $\geq 12$ years) [7].

The pharmacokinetics (PK)/pharmacodynamics (PD), efficacy, and tolerability of linezolid have been extensively studied in different Western subpopulations (including men/women, children/adults, young/elderly, healthy volunteers/obese, those with mild/severe renal impairment, and the critically ill) [8-16]. Following oral dosing, peak plasma concentrations are reached after approximately 1 to $2 \mathrm{~h}$ and the absolute bioavailability is approximately $100 \%$ [8-10,17-20].

*Corresponding author: Huifen Faye Wang, Pfizer Inc., 445 Eastern Point Road Groton, CT 06340, USA, Tel: 001860441 5063; Fax: 001860715 9499; E-mail: huifen.f.wang@pfizer.com

Received August 06, 2014; Accepted September 23, 2014; Published September 26, 2014

Citation: Zhang J, Zhang Y, Wang R, Alvey C, Wang Q, et al. (2014) Pharmacokinetics and Bioequivalence Comparison of $600 \mathrm{mg}$ Single-Dose Linezolid Oral Suspension and Tablet Formulation in Healthy Chinese Subjects. J Bioequiv Availab 6: 153-157. doi:10.4172/jbb.1000197

Copyright: ( 2014 Zhang J, et al. This is an open-access article distributed under the terms of the Creative Commons Attribution License, which permits unrestricted use, distribution, and reproduction in any medium, provided the original author and source are credited. 
Studies have shown no significant differences in area under the plasma concentration-time profile (AUC) values following administration in the fed or fasted state $[17,18,21]$. Steady-state volume of distribution is limited to the total body water content of 30 to 50 liters [11]. Plasma protein binding is concentration-independent and approximately $31 \%$ [11]. Linezolid is primarily metabolized by oxidation of the morpholine ring to form two inactive ring-opened carboxylic acid metabolites. In vitro studies have demonstrated that linezolid is minimally metabolized and may be mediated by human cytochrome P450 (CYP). However, the metabolic pathway of linezolid is not fully understood. About $30 \%$ of the administered dose is eliminated unchanged in the urine, and the low renal clearance (averaged about $40 \mathrm{~mL} / \mathrm{min}$ ) suggests net tubular reabsorption. The mean elimination half-life $\left(t_{1 / 2}\right)$ of linezolid is 4 to $7 \mathrm{~h}$ in adults $[8-10,17,18,20]$. Linezolid is a reversible, nonselective inhibitor of monoamine oxidase. Therefore, linezolid has the potential for interaction with adrenergic and serotonergic agents [7].

Oral tablet formulation of medication can be problematic for those who have difficulty swallowing solid oral dosage forms, especially pediatric patients, geriatric patients, or patients with feeding tubes, and the oral suspension formulation offers an alternative means of providing medications to such patients. Although a linezolid oral tablet formulation is available in China [22], information on the bioavailability and PK properties of linezolid in the Chinese population are scarce.This article reports the data from a PK study conducted in China to evaluate the bioavailability of single-dose oral suspension of linezolid relative to the reference oral film-coated tablet at $600 \mathrm{mg}$ to obtain registration approval of the oral suspension.

\section{Methods}

\section{Study design}

This was a randomized, open-label, two-way cross-over, singledose study conducted in a single site in China (Institute of Antibiotics, Hua Shan Hospital Affiliated to Fudan University, Shanghai, China; www.clinicaltrials.gov identifier: NCT01055769) from March to April 2010. The aim was to establish bioequivalence (primary objective) of single-dose linezolid oral suspension (Zyvox', Pfizer Inc., New York, NY, US; lot \#09-079488) to single-dose linezolid tablet (Zyvox', Pfizer Inc., New York, NY, US; lot \#10-081676) and to evaluate the safety and tolerability (secondary objective) of single-dose linezolid oral suspension and single-dose linezolid tablet in healthy Chinese male subjects under fasted conditions.

The study was conducted in compliance with the ethical principles originating in or derived from the Declaration of Helsinki and in compliance with all International Conference on Harmonization Good Clinical Practice Guidelines. All local regulatory requirements were followed; in particular, those affording greater protection to the safety of study participants. The final protocol, any amendments, and informed consent documentation were reviewed and approved by the Independent Ethics Committee at the investigational center participating in the study (Hua Shan Hospital Affiliated to Fudan University, Shanghai, China).

\section{Study participants}

Eligible subjects were healthy males aged 18 to 40 years (as per Chinese regulatory guidance for bioequivalence studies [23]) with a body mass index (BMI) of 19.0 to $24.0 \mathrm{~kg} / \mathrm{m}^{2}$ and a total body weight $>50 \mathrm{~kg}(110 \mathrm{lbs})$, who provided informed consent and were willing and able to comply with all scheduled visits, treatment plan, laboratory tests, and other study procedures. Subjects were deemed healthy if there were no clinically-relevant abnormalities identified by a detailed medical history, full physical examination (including blood pressure and pulse rate measurement), 12-lead electrocardiogram (ECG), or clinical laboratory tests.

Subjects with any evidence or history of clinically significant disease, allergy or abnormality, positive hepatitis B surface antigen, anti-hepatitis $\mathrm{C}$ virus antibody or HIV serology results, with a history of excess consumption of alcohol or tobacco, with any condition possibly affecting drug absorption (e.g., gastrectomy) or who had consumed grapefruit or grapefruit-containing products within 7 days of first study drug dose, who were taking any medicinal product inhibiting monoamine oxidase A or B, strong CYP inducers, sympathomimetic agents, vasopressive agents, or dopaminergic agents within the 2 weeks prior to first study drug dosing, or who had received treatment with an investigational drug within 90 days or five half-lives, whichever is longer, prior to first study drug dosing, were excluded from the study.

Screening assessments occurred within 28 days prior to the first dose of study drug in the first treatment period. Subjects were admitted to the Clinical Research Unit (CRU) the day before dosing and were required to remain at the $\mathrm{CRU}$ for intensive $\mathrm{PK}$ sampling during each period. Subjects were required to abstain from alcohol, caffeinecontaining products, and smoking at least $48 \mathrm{hr}$ prior to the dose of study medication and during the two treatment periods in-house.

\section{Study treatments}

Enrolled subjects were assigned to receive each of the following two treatments in random order according to a computer-generated randomization schedule: a single dose linezolid oral suspension 600 $\mathrm{mg}$ ( $30 \mathrm{~mL}$; Test treatment) administered using a syringe with 210 $\mathrm{mL}$ of water (in a total of $240 \mathrm{~mL}$ of water) under fasted conditions, or a single dose linezolid $600 \mathrm{mg}$ film-coated oral tablet (Reference treatment) administered whole (without chewing) with $240 \mathrm{~mL}$ water under fasted conditions. The washout period between the two treatments periods was at least 4 days. Subjects were required to fast overnight (for a minimum of $10 \mathrm{~h}$ pre-dose) and for $4 \mathrm{~h}$ post-dose. Study drug was administered in the morning after an overnight fast during each treatment period. In order to standardize the conditions on PK sampling days, all subjects were required to refrain from lying down (except when required for blood pressure, pulse rate, and ECG measurements), eating, and drinking beverages during the first $4 \mathrm{~h}$ after dosing. Water was permitted until $1 \mathrm{~h}$ prior to, and $2 \mathrm{~h}$ after, study medication administration.

\section{Pharmacokinetic evaluation}

In each period, blood samples $(5 \mathrm{~mL})$ were collected in vacutainer tubes containing tripotassium ethylene diaminetetra acetic acid at the following time-points: pre-dose, $0.5,0.75,1,1.5,2,3,4,6,8,12,24$, 36 , and $48 \mathrm{~h}$ post-dose. After sample collection, plasma specimens were separated from whole blood by centrifugation at approximately $1700 \times \mathrm{g}$ for $10 \mathrm{mins}$ at $4^{\circ} \mathrm{C}$, transferred to polypropylene tubes, and stored frozen at approximately $-20^{\circ} \mathrm{C}$ within $1 \mathrm{~h}$ of collection until assayed within the established sample storage stability window as per data generated during method validation.

Plasma samples were analyzed for linezolid concentrations at WuXi AppTec (Shanghai, China) using a validated high-performance liquid chromatography tandem mass spectrometric (HPLC-MS/MS) method. Calibration standard responses were linear over the range of 20.0 to $10,000 \mathrm{ng} / \mathrm{mL}$; using a weighted $\left(1 /\right.$ concentration $\left.^{2}\right)$ linear regression. Those samples with concentrations above the upper limits 
Citation: Zhang J, Zhang Y, Wang R, Alvey C, Wang Q, et al. (2014) Pharmacokinetics and Bioequivalence Comparison of 600 mg Single-Dose Linezolid Oral Suspension and Tablet Formulation in Healthy Chinese Subjects. J Bioequiv Availab 6: 153-157. doi:10.4172/jbb.1000197

of quantification were adequately diluted into calibration range. The lower limit of quantification (LLOQ) for linezolid was $20.0 \mathrm{ng} / \mathrm{mL}$. The between-day assay accuracy (expressed as percent relative error) of the quality control samples at QC-Low $(60.0 \mathrm{ng} / \mathrm{mL})$, QC-Middle $1(500 \mathrm{ng} / \mathrm{mL})$, QC-Middle $2(3500 \mathrm{ng} / \mathrm{mL})$, QC-High $(8000 \mathrm{ng} / \mathrm{mL})$, and dilution QC $(20,000 \mathrm{ng} / \mathrm{mL})$ ranged from 0.5 to $2.0 \%$, and the assay precision (expressed as the between-day percent coefficient of variation $[\% \mathrm{CV}])$ was $\leq 4.3 \%$.

The PK parameters were AUC from time zero to the time of the last quantifiable concentration $\left(\mathrm{AUC}_{\text {last }}\right)$, AUC from time zero extrapolated to infinite time $\left(\mathrm{AUC}_{\text {inf }}\right)$, maximum plasma concentration $\left(\mathrm{C}_{\max }\right)$, time for maximum plasma concentration $\left(\mathrm{T}_{\max }\right)$, and $\mathrm{t}_{1 / 2}$. Non-compartmental analysis of concentration-time data was used to calculate the PK parameters, employing internal electronic noncompartmental analysis software (eNCA version 2.2.1). AUC was calculated using the linear-log trapezoidal method, $\mathrm{C}_{\text {max }}$ and $\mathrm{T}_{\max }$ were reported as observed, and $\mathrm{t}_{1 / 2}$ was calculated as $\ln 2 / \mathrm{k}_{\mathrm{el}}$, where $\mathrm{k}_{\mathrm{el}}$ is the slope of the log-linear terminal portion of the concentration-time curve. Samples below the LLOQ were set to $0 \mathrm{ng} / \mathrm{mL}$ and actual sample collection times were usedto conduct the PK analysis.

\section{Safety evaluation}

Subject safety was monitored throughout the study by physical examination, ECG, laboratory test results, recording of vital signs, and clinical interview for solicitation of adverse events (AEs).

\section{Statistical analyses}

Natural log transformed $\mathrm{AUC}_{\text {inf }}, \mathrm{AUC}_{\text {last }}$, and $\mathrm{C}_{\max }$ of linezolid (normally distributed data) were analyzed (SAS version 9.2) using a linear mixed-effect model with sequence, period, and treatment as fixed effects and subject within sequence as a random, mixed module procedure. Estimates of the adjusted mean differences (Test treatmentReference treatment) and corresponding 90\% confidence intervals (CIs) were exponentiated to provide estimates of the ratio of adjusted geometric means (Test treatment/Reference treatment) and 90\% CIs. Bioequivalence was concluded if the $90 \%$ CIs for the ratio of adjusted geometric means for both $\mathrm{AUC}_{\text {last }}$ and $\mathrm{C}_{\max }$ were completely within the boundaries of 80 to $125 \%$. Descriptive statistics were used to summarize the PK parameters, including $\mathrm{AUC}_{\text {inf }}, \mathrm{AUC}_{\text {last }}$, and $\mathrm{C}_{\max }, \mathrm{T}_{\max }$, and $\mathrm{t}_{1 / 2}$.

A sample size of 18 completers (nine subjects per sequence) was planned to provide at least $96 \%$ power that the $90 \%$ CI for the ratio of Test treatment to Reference treatment for $\mathrm{AUC}_{\text {last }}$ would lie within the acceptance region of 80 to $125 \%$, and $99 \%$ power that $90 \%$ CI for the ratio of Test treatment to Reference treatment for $\mathrm{C}_{\text {max }}$ would lie within the acceptance region of 80 to $125 \%$. Consequently, this sample size provided at least $95 \%$ power overall to demonstrate bioequivalence of the Test treatment to the Reference treatment for both $\mathrm{AUC}_{\text {last }}$ and $\mathrm{C}_{\max }$ based on the assumption that the true ratio between Test treatment and Reference treatment for both $\mathrm{AUC}_{\text {last }}$ and $\mathrm{C}_{\max }$ is 1.05 . The power calculations assumed the estimates of within-subject standard deviations (SD) as 0.1405 for $\ln \left(\mathrm{AUC}_{24}\right)$ and 0.1147 for $\ln \left(\mathrm{C}_{\mathrm{mx}}\right)$. Assuming an approximate dropout rate of $10 \%, 20$ subjects were recruited into the study to ensure 18 completers.

\section{Results}

\section{Study population}

All 20 enrolled subjects completed the study and were included in the PK and safety analyses. Subjects were all Chinese males, had an overall mean \pm SD age of $25.4 \pm 2.1$ years (range 22-29 years), weighed a mean $\pm S D$ of $65.3 \pm 6.8 \mathrm{~kg}$ (range $55.0-77.0 \mathrm{~kg}$ ), and had an overall mean \pm SD BMI of $22.1 \pm 1.2 \mathrm{~kg} / \mathrm{m}^{2}$ (range $20.1-24.0 \mathrm{~kg} / \mathrm{m}^{2}$ ). None of the study subjects received prior or concomitant drug or non-drug treatments.

\section{Pharmacokinetics}

The mean $( \pm \mathrm{SD})$ plasma linezolid concentration-time profiles for both treatments are displayed in Figure 1 and PK parameters summarized in Table 1 . The absorption of the linezolid oral suspension formulation was slightly faster than that of the tablet formulation with the median $\mathrm{T}_{\text {max }}$ at $0.63 \mathrm{~h}$ and $1.50 \mathrm{~h}$, respectively. Following attainment of $\mathrm{C}_{\max }$, mean linezolid plasma concentrations declined in parallel

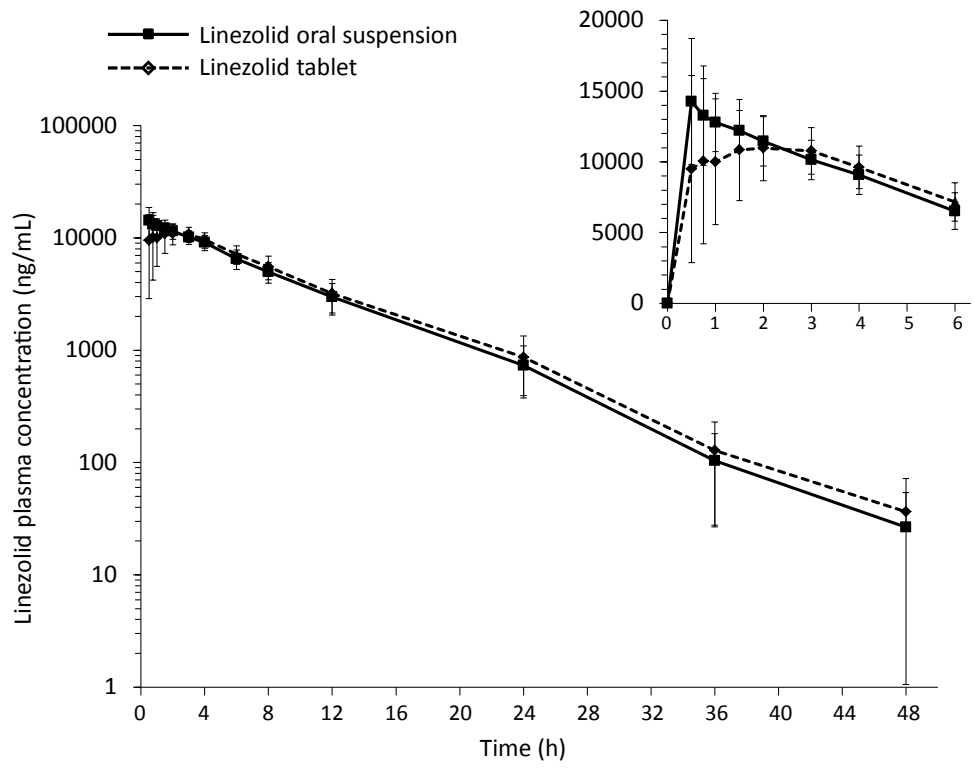

Figure 1: Mean $( \pm S D)$ plasma linezolid concentration-time profiles following single oral doses of 600 mg oral suspension and 600 mg tablet formulations in healthy Chinese subjects $(\mathrm{N}=20)$; 0-48 $\mathrm{h}$ on log-linear scale, and 0-6 h on linear-linear scale [insert]. 


\begin{tabular}{|c|c|c|}
\hline Parameter (Units) & $\begin{array}{c}\text { Linezolid 600 mg tablet } \\
\text { (Reference treatment) } \\
\mathbf{N = 2 0}\end{array}$ & $\begin{array}{c}\text { Linezolid 600 mg } \\
\text { oral suspension } \\
\text { (Test treatment) } \\
\mathbf{N = 2 0}\end{array}$ \\
\hline $\mathrm{AUC}_{\text {inf }}\left(\mu \mathrm{g}^{*} \mathrm{~h} / \mathrm{mL}\right)$, mean $( \pm \mathrm{SD})^{*}$ & $112.6(24.9)$ & $109.2(21.7)$ \\
\hline $\mathrm{AUC}_{\text {last }}\left(\mu \mathrm{g}^{*} \mathrm{~h} / \mathrm{mL}\right)$, mean $( \pm \mathrm{SD})^{*}$ & $112.0(24.7)$ & $108.9(21.7)$ \\
\hline $\mathrm{C}_{\text {max }}(\mu \mathrm{g} / \mathrm{mL})$, mean $( \pm \mathrm{SD})^{*}$ & $13.7(3.5)$ & $15.5(3.5)$ \\
\hline $\mathrm{T}_{\text {max }}(\mathrm{h})$, median $($ range $)$ & $1.50(0.5-4.0)$ & $0.63(0.5-2.0)$ \\
\hline $\mathrm{t}_{1 / 2}(\mathrm{~h})$, mean $( \pm \mathrm{SD})^{*}$ & $5.13(0.92)$ & $5.08(0.70)$ \\
\hline
\end{tabular}

$A \cup C_{\text {, }}$ area under plasma concentration-time curve from time zero extrapolated to infinite time; AUC, area under plasma concentration-time curve from time zero to the time of the last quantifiable concentration; $\mathrm{C}_{\max }$, maximum plasma concentration; SD: Standard Deviation; $t_{1 / 2}$, elimination half-life; $T_{\max }$, time for maximum plasma concentration.

*Arithmetic mean.

Table 1: Descriptive summary of pharmacokinetic parameters of plasma linezolid following single oral doses of $600 \mathrm{mg}$ oral suspension and $600 \mathrm{mg}$ tablet formulations in healthy Chinese subjects.

\begin{tabular}{|c|c|c|c|c|}
\hline & \multicolumn{2}{|c|}{ Geometric mean } & & \\
\hline $\begin{array}{c}\text { Parameter } \\
\text { (Units) }\end{array}$ & $\begin{array}{c}\text { Reference } \\
\text { (linezolid } \\
\text { tablet), N=20 }\end{array}$ & $\begin{array}{c}\text { Test } \\
\text { (linezolid oral } \\
\text { suspension), } \\
\mathbf{N = 2 0}\end{array}$ & $\begin{array}{c}\text { Ratio* } \\
\text { (\%) }\end{array}$ & $\begin{array}{c}\mathbf{9 0 \%} \text { Cl for ratio } \\
\text { (\%) }\end{array}$ \\
\hline $\mathrm{AUC}_{\text {inf }}\left(\mu \mathrm{g}^{*} \mathrm{~h} / \mathrm{mL}\right)$ & 109.8 & 107.2 & 97.65 & $92.92-102.63$ \\
\hline $\mathrm{AUC}_{\text {last }}\left(\mu \mathrm{g}^{*} \mathrm{~h} / \mathrm{mL}\right)$ & 109.3 & 106.9 & 97.81 & $93.11-102.75$ \\
\hline $\mathrm{C}_{\text {max }}(\mu \mathrm{g} / \mathrm{mL})$ & 13.3 & 15.2 & 113.67 & $105.26-122.75$ \\
\hline
\end{tabular}

$\mathrm{AUC}_{\mathrm{iff}}$, area under plasma concentration-time curve from time zero extrapolated to infinite time; $A \cup C_{\text {last, }}$, area under plasma concentration-time curve from time zero to the time of the last quantifiable concentration; $\mathrm{Cl}$ : Confidence Interval; $\mathrm{C}_{\text {max }}$, maximum plasma concentration; CV, Coefficient of Variation.

${ }^{*}$ Ratio of adjusted geometric mean for Test treatment (linezolid $600 \mathrm{mg}$ oral suspension) versus Reference treatment (linezolid $600 \mathrm{mg}$ tablet).

Table 2: Statistical summary of treatment comparison.

between both formulations. Mean terminal $\mathrm{t}_{1 / 2}$ was about $5.1 \mathrm{~h}$ for both treatments. Total and peak exposures $\left(\mathrm{AUC}\right.$ and $\mathrm{C}_{\max }$ ) to linezolid were similar between treatments following single-dose administration of the $600 \mathrm{mg}$ oral suspension and the $600 \mathrm{mg}$ tablet formulations. Intersubject variability in exposure was also similar for both formulations, based on \%CV values of $20-22 \%$ for $\mathrm{AUC}_{\text {last }}$ and $\mathrm{AUC}_{\text {inf }}$ and $23-26 \%$ for $\mathrm{C}_{\max }$.

Results of the statistical analysis for bioequivalence are presented in Table 2. The bounds of the $90 \%$ CI for the ratios of adjusted geometric means (linezolid oral suspension/tablet) for both $\mathrm{AUC}_{\text {last }}$ and $\mathrm{C}_{\max }$ were completely within the 80 to $125 \%$ range, indicating that linezolid 600 mg oral suspension and $600 \mathrm{mg}$ tablet formulations were bioequivalent. Results for $\mathrm{AUC}_{\text {inf }}$ were nearly identical to those for $\mathrm{AUC}_{\text {last }}$, and were also completely within the 80 to $125 \%$ range.

\section{Adverse events}

There were no AEs reported following the treatment with the linezolid $600 \mathrm{mg}$ oral suspension, and one subject receiving the linezolid $600 \mathrm{mg}$ tablet reported one treatment-emergent $\mathrm{AE}$ of mild abdominal pain that was not treatment-related and that resolved after $3.4 \mathrm{~h}$. There were no deaths, serious AEs, permanent discontinuations due to AEs, or dose reductions or temporary discontinuations due to AEs reported in this study, nor were there any clinically significant abnormalities in laboratory test data, vital signs, or ECG values.

\section{Discussion}

The primary objective of this study was to establish bioequivalence of a single dose of linezolid $600 \mathrm{mg}$ oral suspension to $600 \mathrm{mg}$ tablet formulation in healthy Chinese male subjects to obtain regulatory approval for the oral suspension formulation. When administered as an oral suspension $(600 \mathrm{mg})$, the total exposure (AUC) to linezolid was nearly identical to that following administration as an oral tablet $(600$ $\mathrm{mg}$ ). The bounds of the $90 \%$ CIs for the ratios of adjusted geometric means for all three primary exposure comparisons $\mathrm{AUC}_{\text {last }}, \mathrm{AUC}_{\text {inf }}$, and $\mathrm{C}_{\max }$, were completely within the established equivalence limits of 80 to $125 \%$. Based on these results, the linezolid $600 \mathrm{mg}$ oral suspension is bioequivalent to the $600 \mathrm{mg}$ tablet formulation and they are anticipated to be therapeutically equivalent and could be switched in subjects without any need for dose modification. The single doses of linezolid $600 \mathrm{mg}$ oral suspension and $600 \mathrm{mg}$ tablet formulation were safe and well-tolerated in healthy Chinese male subjects.

Linezolid has been available in China since 2007, but there are only a few reports on the PK and/or PD of linezolid in the Chinese population. The $\mathrm{PK} / \mathrm{PD}$ profile of intravenous linezolid in eight critically ill Chinese patients with Gram-positive bacterial infections was reported to vary widely following twice-daily dose at $600 \mathrm{mg} /$ dose, including a 5-7-fold difference in $\mathrm{C}_{\text {max }}$ (ranged from 5.57 to $27.08 \mathrm{mg} / \mathrm{L}$ with a mean $\pm \mathrm{SD}$ of $15.70 \pm 6.58 \mathrm{mg} / \mathrm{L}$ ) and $\mathrm{AUC}_{(0-12)}$ (ranged from 31.66 to $216.82 \mathrm{mg} \times \mathrm{h} / \mathrm{L}$ with a mean $\pm \mathrm{SD}$ of $96.73 \pm 56.45 \mathrm{mg} \times \mathrm{h} / \mathrm{L}$ ) [24]. Wide linezolid serum exposures were also reported in Western populations following intermittent infusion $(600 \mathrm{mg} / 12 \mathrm{~h})$ or continuous infusion $(300 \mathrm{mg}$ intravenous loading dose $+900 \mathrm{mg}$ continuous infusion, followed by $1200 \mathrm{mg} /$ daily) [16]. Recently, Cai et al. evaluated the PK/PD properties of linezolid in healthy male Chinese volunteers with low $(>50-\leq 55 \mathrm{~kg})$ and high $(\geq 80 \mathrm{~kg}$ ) body weights following a single intravenous dose $(600 \mathrm{mg} / 30 \mathrm{~min})$ versus a weight-adjusted dose $(10 \mathrm{mg} / \mathrm{kg} / 30 \mathrm{~min})$ [25]. Plasma concentrations were much higher in Chinese subjects with low body weight than in those with high body weight when a fixed dose was administered. Diminished serum concentrations following oral administration of linezolid have also previously been observed in obese Western populations [14], which is consistent with the reported population PK of linezolid indicating that body weight is one of the influential covariates on its clearance and distribution volume $[15,26]$.

In our study in healthy Chinese adults, the observed geometric means for $\mathrm{C}_{\max }$ were $15 \mu \mathrm{g} / \mathrm{mL}$ and $13 \mu \mathrm{g} / \mathrm{mL}$ andfor AUC $_{\text {inf }}$ were $107 \mu \mathrm{g} \times \mathrm{h} / \mathrm{mL}$ and $110 \mu \mathrm{g} \times \mathrm{h} / \mathrm{mL}$, following single-dose linezolid 600 $\mathrm{mg}$ oral suspension and single-dose linezolid $600 \mathrm{mg}$ oral tablet, respectively. These findings are in line with those reported in Western populations following a single-dose of $600 \mathrm{mg}$ linezolid oral tablets and oral suspension [21]. The reported mean $( \pm \mathrm{SD})$ for $\mathrm{C}_{\max }$ were 11.00 $( \pm 2.76) \mu \mathrm{g} / \mathrm{mL}$ and $12.70( \pm 3.96) \mu \mathrm{g} / \mathrm{mL}$ and for $\mathrm{AUC}_{\text {inf }}$ were 80.80 $( \pm 35.10) \mu \mathrm{g} \times \mathrm{h} / \mathrm{mL}$ and $91.40( \pm 39.30) \mu \mathrm{g} \times \mathrm{h} / \mathrm{mL}$, for oral suspension and oral tablet formulations, respectively. Similar results were reported from a randomized, open-label, two-way cross-over, single-dose PK study in 28 healthy adult Egyptian males [27], which also showed that the rate and extent of absorption of linezolid $600 \mathrm{mg}$ oral suspension formulation was comparable to that of linezolid $600 \mathrm{mg}$ tablet formulation; mean arithmetic $\mathrm{AUC}_{\text {inf }}$ for the suspension compared with the tablet were $120 \mu \mathrm{g} \times \mathrm{h} / \mathrm{mL}$ and $128 \mu \mathrm{g} \times \mathrm{h} / \mathrm{mL}$, respectively, and mean arithmetic $\mathrm{C}_{\max }$ were $9.4 \mu \mathrm{g} / \mathrm{mL}$ and $9.2 \mu \mathrm{g} / \mathrm{mL}$, respectively [27].

\section{Conclusions}

Based on the results of our study, linezolid $600 \mathrm{mg}$ oral suspension and linezolid $600 \mathrm{mg}$ tablets are anticipated to be therapeutically equivalent in healthy Chinese subjects and could be switched in subjects without any need for dose modification. Both formulations were safe and well tolerated in this study. 
Citation: Zhang J, Zhang Y, Wang R, Alvey C, Wang Q, et al. (2014) Pharmacokinetics and Bioequivalence Comparison of 600 mg Single-Dose Linezolid Oral Suspension and Tablet Formulation in Healthy Chinese Subjects. J Bioequiv Availab 6: 153-157. doi:10.4172/jbb.1000197

\section{Acknowledgment}

The authors would like to thank Professors Yaoguo Shi and Jufang Wu, Dr. Xiaojie $\mathrm{Wu}$, and Ms.Jicheng Yu from Hua Shan Hospital for their contribution to the conduct of the study. The authors also wish to thank Drs. Kai Wang, Jenny Fu, and Feng Guo, who were all Pfizer employees during this study, for their input in the study design. Additionally, the authors would also like to acknowledge Wuxi Pharm for providing sample analysis for quantitation of plasma linezolid. Editorial support in the form of preparing the manuscript for submission was provided by Anne Jakobsen, MSc of Engage Scientific Solutions and funded by Pfizer Inc.

\section{Conflict of Interest}

This study was sponsored by Pfizer Inc. (www.clinicaltrials.gov identifier: NCT01055769). Jing Zhang and Yingyuan Zhang were the Principal Investigators for the study from Hua Shan Hospital, China. Ronnie Wang, Christine Alvey, Qiang Wang, Bharat Damle,and Huifen Faye Wang were employees of Pfizer Inc. The study sponsor, Pfizer Inc., and the manuscript authors were involved in study design; collection, analysis, and interpretation of data; in the writing of the manuscript; and in the decision to submit the manuscript for publication.

\section{References}

1. Swaney SM, Aoki H, Ganoza MC, Shinabarger DL (1998) The oxazolidinone linezolid inhibits initiation of protein synthesis in bacteria. Antimicrob Agents Chemother 42: 3251-3255.

2. Fung HB, Kirschenbaum HL, Ojofeitimi BO (2001) Linezolid: an oxazolidinone antimicrobial agent. Clin Ther 23: 356-391.

3. Perry CM, Jarvis B (2001) Linezolid: a review of its use in the management of serious gram-positive infections. Drugs 61: 525-551.

4. Kaya O, Akcam FZ, Temel EN (2008) In vitro activities of linezolid and tigecycline against methicillin-resistant Staphylococcus aureus strains. Microb Drug Resist 14: 151-153.

5. Zurenko GE, Yagi BH, Schaadt RD, Allison JW, Kilburn JO, et al. (1996) In vitro activities of $U-100592$ and $U-100766$, novel oxazolidinone antibacterial agents. Antimicrob Agents Chemother 40: 839-845.

6. Dresser LD, Rybak MJ (1998) The pharmacologic and bacteriologic properties of oxazolidinones, a new class of synthetic antimicrobials. Pharmacotherapy 18: 456-462.

7. Pharmacia and Upjohn Company, Division of Pfizer Inc, New York, NY (2014) Zyvox® (Linezolid) [US package insert]

8. Stalker DJ, Jungbluth GL (2003) Clinical pharmacokinetics of linezolid, a nove oxazolidinone antibacterial. Clin Pharmacokinet 42: 1129-1140.

9. Stalker DJ, Jungbluth GL, Hopkins NK, Batts DH (2003) Pharmacokinetics and tolerance of single- and multiple-dose oral or intravenous linezolid, an oxazolidinone antibiotic, in healthy volunteers. J Antimicrob Chemother 51 $1239-1246$.

10. Stalker DJ, Wajszczuk CP, Batts DH (1997) Linezolid safety, tolerance and pharmacokinetics following oral dosing twice daily for 14.5 days. Proceedings of the Thirty-Seventh Interscience Conference on Antimicrobial Agents and Chemotherapy, Toronto, Canada.

11. Sisson TL, Jungbluth GL, Hopkins NK (2002) Age and sex effects on the pharmacokinetics of linezolid. Eur J Clin Pharmacol 57: 793-797.

12. Kearns GL, Abdel-Rahman SM, Blumer JL, Reed MD, James LP, et al. (2000) Single dose pharmacokinetics of linezolid in infants and children. Pediatr Infect Dis J 19: 1178-1184

13. Brier ME, Stalker DJ, Aronoff GR, Batts DH, Ryan KK, et al. (2003) Pharmacokinetics of linezolid in subjects with renal dysfunction. Antimicrob Agents Chemother 47: 2775-2780.
14. Stein GE, Schooley SL, Peloquin CA, Kak V, Havlichek DH, et al. (2005) Pharmacokinetics and pharmacodynamics of linezolid in obese patients with cellulitis. Ann Pharmacother 39: 427-432.

15. Bhalodi AA, Papasavas PK, Tishler DS, Nicolau DP, Kuti JL (2013) Pharmacokinetics of intravenous linezolid in moderately to morbidly obese adults. Antimicrob Agents Chemother 57: 1144-1149.

16. Adembri C, Fallani S, Cassetta MI, Arrigucci S, Ottaviano A, et al. (2008) Linezolid pharmacokinetic/pharmacodynamic profile in critically ill septic patients: intermittent versus continuous infusion. Int $\mathrm{J}$ Antimicrob Agents 31 : 122-129.

17. Welshman IR, Sisson TA, Jungbluth GL, Stalker DJ, Hopkins NK (2001) Linezolid absolute bioavailability and the effect of food on oral bioavailability. Biopharm Drug Dispos 22: 91-97.

18. Welshman IR, Stalker DJ, Wajsczuk CP (1998) Assessment of absolute bioavailability and evaluation of the effect of food on oral bioavailability of linezolid. Anti-Infective Drugs Chemother 16: 54

19. Slatter JG, Stalker DJ, Feenstra KL, Welshman IR, Bruss JB, et al. (2001) Pharmacokinetics, metabolism, and excretion of linezolid following an oral dose of $[(14) C]$ linezolid to healthy human subjects. Drug Metab Dispos 29: 11361145.

20. Hendershot PE, Antal EJ, Welshman IR, Batts DH, Hopkins NK (2001) Linezolid: pharmacokinetic and pharmacodynamic evaluation of coadministration with pseudoephedrine $\mathrm{HCl}$, phenylpropanolamine $\mathrm{HCl}$, and dextromethorpan $\mathrm{HBr}$. J Clin Pharmacol 41: 563-572.

21. Pharmacia and Upjohn Company, Division of Pfizer Inc, New York, NY, USA (2014) United States Prescribing Information.

22. Pharmacia and Upjohn Company, Division of Pfizer Inc (2008) Linezolid Tablets (LinaizuoanPian), Si WolZyvox, [China package insert]

23. China Food and Drug Administration, H GCL2-1 (2005) Technical guidance on human bioavailability and bioequivalence studies of synthetic drugs.

24. Dong H, Wang X, Dong Y, Lei J, Li H, et al. (2011) Clinical pharmacokinetic pharmacodynamic profile of linezolid in severely ill intensive care unit patients. Int J Antimicrob Agents 38: 296-300.

25. Cai Y, Chai D, Falagas ME, Karageorgopoulos DE, Wang R, et al. (2013) Weightadjusted versus fixed dose of linezolid for Chinese healthy volunteers of higher and lower body weight: a Phase I pharmacokinetic and pharmacodynamic study. Expert Opin Investig Drugs 22: 309-315.

26. Abe S, Chiba K, Cirincione B, Grasela TH, Ito K, et al. (2009) Population pharmacokinetic analysis of linezolid in patients with infectious disease: application to lower body weight and elderly patients. J Clin Pharmacol 49 1071-1078.

27. Helmy SA (2013) Pharmacokinetics and relative bioavailability evaluation of linezolid suspension and tablet formulations. Drug Res (Stuttg) 63: 489-494. 